\title{
Identidade e lugar na metafenomenologia da alteridade Payayá ${ }^{1}$
}

\begin{abstract}
Resumo
A relação lugar-identidade apresenta uma ambivalência que vai da celebração à condenação, ganhando novo fôlego após os anos 1990 tanto com a relevância que os movimentos identitários de resistência (étnicos, raciais e de gênero) alcançaram, na luta pelo lugar, enquanto território, quanto na força que o clamor pelo respeito à diferença e pelo reconhecimento do sentido opressor e colonial da identidade receberam, questionando o papel dos processos de territorialização nos conflitos e na negação da diferença que promovem a captura do Outro pelo Mesmo. Deslocamos a questão da relação identidade-diferença para o nexo consciência-lugar, desfazendo esta associação que dá relevo ao sentido frente ao sem-sentido. A prevalência da consciência é compreendida como um dos instrumentos da razão imperialista-coIonizadora, eurocêntrica, e por isso é necessário fissurá-la para um outro sentido geográfico de identidade. Mas como significar nossa relação geográfica e sua implicação para a identidade libertando-se das amarras da consciência e dos modelos coloniais de intelecção do ser? Este é o principal questionamento mobilizador do artigo, o qual será enfrentado a partir da experiência com os indígenas Payayá e da interlocução com a filosofia de Emmanuel Lévinas, como metafenomenologia, no sentido de um pensamento descolonial latino-americano.
\end{abstract}

Palavras-chave: Yby, Povos indígenas, Ética da alteridade, Colonialidade, Emmanuel Lévinas.

\section{Abstract \\ IDENTITY AND PLACE IN THE METAPHENOMENOLOGY OF THE PAYAYÁ'S ALTERITY \\ The identity-place relationship presents an ambivalence that goes from celebration to condemnation, gaining a new impetus after the 1990s, both with the relevance}


that identity resistance movements (ethnic, racial and gender) have achieved, fighting for the place - as territory -, as with the strength that crying for respect differences and the oppressive and colonial sense of identity received, questioning the role of the territorialization processes in the conflicts and in the denial of the distinctions that promote the capture of the Other by the Same. We move the question of the identity-difference relationship to the nexus between consciousness-place, undoing this association that gives relevance to sense in the face of the non-sense. The prevalence of consciousness is understood as one of the instruments of the imperialist colonizing reason, Eurocentric, and therefore it is necessary to break it into another geographical sense of identity. But how do we give meaning to our geographical relationship and its implication to identity, freeing ourselves from the bonds of consciousness and the colonial models of the intellection of being? This is the main question that mobilized the paper, which will be faced from the experience with the Payayá natives and the interlocution with the philosophy of Emmanuel Lévinas, as methaphenomenology, toward a Latin American descolonial thinking.

Key-words: Yby, Ethics of alterity, Indigenous people, Coloniality, Emmanuel Lévinas.

\section{Os essencialismos da identidade e o descarte da questão geográfica}

O tema identidade tem ocupado a agenda contemporânea de distintos movimentos sociais, como estratégia política de militância para o enfrentamento da ancilose social e cultural pouco afeita à alteridade. Reclama-se o direito à autoidentificação, o respeito à coexistência da multiplicidade e, simultaneamente, a superação da lógica binária da Modernidade, que impõe linearidades históricas e hierarquias culturais por meio de uma razão metonímica, a qual, segundo o sociólogo português Boaventura Santos (2006), consiste na primazia da totalidade sob a forma de ordem. Essa razão sufoca a pluralidade, policiando as manifestações identitárias que subvertem a excentricidade da sua matriz autoritária e seletiva.

Nesse contexto, a ênfase no direito à igualdade como lastro basilar que garante a manifestação da diferença, tem sido um dos principais motivos que gravitam em torno da temática da identidade. Tornada bandeira, ela é veículo do questionamento do estatuto da tirania totalitária, do proselitismo e do caráter obsedante de coerção das minorias.

No entanto, de maneira geral, ao contrário da elasticidade defendida pelos movimentos sociais, academicamente o tema da identidade passou 
a ser rechaçado nos últimos anos por sua significação enclausurante. Grande parte das críticas se sustenta na relação estreita entre identidade, controle e fixidez, uma vez que quaisquer formas de identificação são concebidas como mecanismos de opressão e aprisionamento do ser humano em um tempo-espaço cristalizado. Há, pois, uma valorização da fluidez e do movimento, reconhecidos como prenúncio de libertação e destituição de fronteiras, acentuadas pelos novos modos de comunicação e de sociabilidade.

Na ciência geográfica, esta leitura produziu uma crítica à Geografia Clássica, acusada de recorrer a perspectivas naturalistas para estigmaticamente relacionar grupos ou povos com lugares ou regiões (LE BOSSÉ, 2004). De maneira intransitiva, esta Geografia é retratada pela permanência e pela unicidade com as quais ancorou sujeitos em espaços demarcados e fechados.

No entanto, essas críticas apenas ladeiam o problema da identidade. O princípio lógico da não contradição, mediante o movimento do eu ao encontro de si, marca o curso de retorno ao Mesmo. A identidade é simplesmente tautológica, revestida pela dramática coincidência de que o eu é si mesmo. O aprisionamento não é dado pela relação conservadora entre pessoas e suas respectivas temporalidades e espacialidades. Ele é anterior, se encontra no vir-a-ser-de-si-mesmo, reiterado pelos modelos da tradição metafísica ocidental e mesmo pela fenomenologia.

Ainda que a reflexão de si seja realizada a partir de um sujeito sociológico, no qual o indivíduo não se encontra isolado, mas localizado em meio a relações sociais, não se rompe com o encadeamento do eu a si, caso persistamos na estrutura de um eu que se escuta e se tateia. Isto sem falar na concepção de identidade coletiva, na qual o imbróglio da positividade da igualdade persiste e se aprofunda. Além de envolver a discussão sobre representação, conceber um coletivo como unificação oriunda de uma constituição lógica de não contradição potencializa alguns problemas. Para muitos, estes seriam de natureza epistemológica, como os que foram identificados por Frederico Araújo (2007): a individuação, a similitude e a permanência. A similitude acaba por exigir unicidade (individuação) e estabilidade (permanência ou durabilidade) para possibilitar comparações e classificações com outros coletivos formados por "iguais". Essa celeuma fundamenta a substancialização da identidade. 
Sob esse ponto de vista, falar em identidade de um povo pressupõe a consumação de um movimento de centralidade de um coletivo consagrado como o Mesmo, ou como dado que se mostra enquanto estabilidade substancial. Os povos indígenas estariam, nesse contexto, em derrocada, pois todo seu devir estaria amarrado a insígnias de uma originalidade fundadora, impedindo-os de se dizer indígenas caso não correspondam ao aborígene tipicamente nu, que habita ocas em meio à mata, comendo em cuias ou em recipientes de cerâmica etc.

Esse movimento nos conduz à vinculação da identidade a um certo tipo de prisão tempo-espacial. Novamente, obnubila-se o fundamento do problema da identidade.

Mas como significar nossa relação geográfica e sua implicação para a identidade libertando-se das amarras coloniais de intelecção do ser? Seguindo uma trilha metafenomenológica, em sentido descolonial, partimos da experiência com os indígenas Payayá, no contexto da realização de nossa tese de doutorado (LIMA, 2019), mas que se amplia em múltiplos sentidos, pessoais, acadêmicos e políticos, em interlocução com a filosofia de Emmanuel Lévinas (1905-1995), em direção a uma outra perspectiva geográfica da identidade.

Lévinas foi um filósofo judeu franco-lituano que repensou a fenomenologia e a metafísica, acentuadamente, a partir da sua experiência com o hitlerismo, o qual impôs uma clandestinidade, o cárcere e o triste privilégio de ter sobrevivido à violência da guerra. A solicitude das vítimas (incluindo muitos dos seus familiares) que morreram ecoando um grito mudo, o conduziu a tensionar a filosofia e a ciência ocidentais, fugindo da anfiobiologia do ente e do ser em favor de uma radicalização da alteridade. Sua crítica à circularidade viciosa do si mesmo fundamentou a Filosofia da Libertação na América Latina por volta da década de 1970, notadamente na figura de Enrique Dussel $(2011$; 2015) que, ao seu modo, combateu a asfixia dos conhecimentos situados, valorizando-os e opondo-se à universalidade de um conhecimento alienígena.

No contexto dos movimentos contemporâneos que colocam em xeque o papel do colonialismo na formação das identidades, retemos a crítica à colonialidade como pano de fundo de uma Geografia que subverta o totalitarismo de reiteração do si mesmo, nos desafiando a 
uma fenomenologia que se preste ao movimento de traumatismo do solipsismo do eu e de acolhimento do Outro. Não um movimento de busca de uma raiz anterior, de uma identidade mais original, no sentido essencialista tão veementemente combatido. Antes, um sentido geográfico da identidade que tenha como base a desnuclearização do nó substancial do eu formado no Mesmo, mediante uma intimação indeclinável da própria alteridade Payayá.

Neste movimento, o lugar aparece de maneira renovada, sem um sentido essencialista do fechamento, mas como a própria alteridade radical.

\section{A crítica metafenomenológica: para além da consciência}

O princípio da identidade, segundo a fórmula $\mathrm{A}=\mathrm{A}$ defendida por Martin Heidegger, filósofo alemão, em seu conhecido texto "Identidade e Diferença" (HEIDEGGER, 1999), não exprime uma estabilidade eternamente dada. Recorrentemente ela é lida como significação de uma imutabilidade que nos objetifica, legando-nos a necessidade de sermos incólumes a qualquer mudança ao longo de nossas vidas para que possamos ser nós mesmos. A identidade, nesse caso, não é ser o mesmo continuadamente, mas é a inerência do eu a si. A igualdade é verbo, A é A, e por isso implica em um dinamismo ou alteração do ente. Na simultaneidade da predicação tautológica, o ente é sujeito e predicado, designado pela verbalidade do verbo. A predicação é temporalização, é ser, e por isso, não pode ser vulgarmente rotulada como fixidez.

A questão não é simplesmente o fantasma da igualdade, mas perpassa a correlação entre identidade e consciência. Muitos pesquisadores dedicados ao estudo da identidade a conceberam, sobretudo, sob um plano psíquico que tematiza, mediante uma consciência objetivadora, o próprio eu e até mesmo o outro. Há um enclausuramento na recorrência do eu a si, na qual o humano se faz mônada. Por isso, apesar de toda a verbalidade que as movimentam, as identidades matemáticas são encontradas no repouso em si e para si. A petrificação se dá pelo solipsismo da primordialidade do eu, que de tão idêntico a si mesmo embriaga-se em seu sentido egológico. A hegemonia é manifesta pelo egoísmo e pelo egotismo. 
Embora mesmo na coincidência consigo seja possível modificar-se sem mudar, ou afastar-se de si sem se abandonar, como Edmund Husserl, pai da fenomenologia, nos possibilitou pensar, a vinculação irrestrita da identidade à consciência é de fato um óbice à alteridade, como destacado por Lévinas (2011).

A partir da fenda aberta por Husserl, a questão da consciência se desdobra de outra maneira. Consciente de um "eu idêntico" no âmbito de um "eu penso", o humano, sob a tematização do ver, percebe a alteridade na imanência em que é vivida. A inquietação se dá no campo do visível. O outro é percebido na temporalidade da sensação, enquanto conteúdo imanente e vivido sob a operação da intencionalidade. Esta abertura da consciência ao ser possibilita a apreensão do que se apresenta e lhe confere relativamente um sentido.

Entretanto, a relação entre identidade, consciência e intencionalidade não é um processo simples e sumariamente objetificador. Percorrendo a fenomenologia, poderíamos seguir várias direções para alimentar esse debate. A princípio, precisamos destacar que uma das maiores formulações de Husserl foi destruir as molduras relativas ao sujeito, ao objeto e à representação (SEBBAH, 2009), o que foi possível graças ao entendimento da consciência como intencionalidade. Isso implica reconhecer que a consciência não é uma fortaleza ensimesmada, pois o próprio dinamismo do visível denuncia que o se voltar a si é puramente originado pelo esforço de evasão (ato de sair de si). E, por isso, a consciência é um ato de transgressão da distância entre ela e o mundo, entre si e o outro.

Por essa via, temos a impressão de que o problema está resolvido. A identidade, em sua proximidade com a consciência nos termos husserlianos, constitui-se pela intencionalidade, e, por isso, o caráter lógico ou tautológico do encadeamento do eu a si é provocado pelo esforço de fuga em direção à alteridade. A "transcendência imanente", como se referiu o filósofo francês François-David Sebbah (2009) para caracterizar a intencionalidade husserliana, possibilita que o presente a si mesmo da identidade e da consciência não é um para si, apesar de em si.

Porém, apesar dessa estrutura da consciência, a relação desta com a identidade por si só já encerra um problema. Primeiro, porque nesta base encontra-se a percepção, a qual é consciência do percebido. Nisto 
enfaticamente insistiu a filosofia de Lévinas ao longo de suas obras, a exemplo de "De outro modo que ser ou para lá da essência" (LÉVINAS, 2011).

O movimento levinasiano tensiona a percepção para se excarcerar da análise do "como" que está intrínseca à tematização do que aparece. Não se trata de indicar a necessidade de ampliar os horizontes de visibilidade, pressupondo alguma insuficiência do visto. A questão não é de tentar recuperar a totalidade a partir de uma parte, incitando à superação, por meio de determinada dialética, de uma certa restrição no campo do ver, como fica explícito no texto de Lévinas "A filosofia e o despertar" (LÉVINAS, 2010). Reconhecer que a percepção se manifesta como "consciência de", nos mostra a indispensabilidade de nos situarmos além dela, para assim fomentar a desestabilização da substância e também da identidade. Por menos intelectualistas que tentemos ser, a interpretação da significação do sensível por via da "consciência de" não possibilita alcançar uma heterogeneidade radical, mas acaba por preconizar um certo imobilismo da fenomenalidade. Dessa maneira, o outro é petrificado pelo confinamento do como ele aparece. Neste contexto, "ser (uma substância) é aparecer; aparecer é ser uma substância” (SEBBAH, 2009, p. 122).

Independentemente do órgão do sentido por meio do qual se percebe, o visto, quando considerado na posição do que se encontra diante de nós, é tornado objeto, e é justamente contra essa objetificação do fora que se sustenta a fenomenologia pós-husserliana, heideggeriana e pós-heideggeriana, como destacou o filósofo francês Michel Henry (2012).

Embora a percepção seja importante, ela é cúmplice do enclausuramento do outro. Mesmo sendo ela fulcral para o sentido, o aparecer e sua correlação com um Dito (tematização do visto), não é fonte de toda a significação, nem tampouco enuncia uma abertura da identidade. $\mathrm{O}$ acesso ao ser por vias da "consciência de", ainda que sob uma noção de consciência alargada, não se dá mediante sua manifestação, como descreve a tradição ocidental da filosofia. Este é um dos caminhos que percorreremos para argumentar a não coincidência do eu consigo mesmo, no desafio de pensar a identidade em diástase, provocada pela alteridade.

O segundo motivo do problema de uma associação inextrincável entre identidade e consciência se sustenta na situação insidiosa que ela pode produzir. A autonomia da consciência e do eu é uma grande falácia, pois 
ambos são condicionados. Este entendimento é partilhado pelos autores estruturalistas (como o antropólogo Claude Lévi-Strauss, por exemplo), como também por muitos críticos da filosofia do sujeito (destacadamente os filósofos Friedrich Nietzsche e Martin Heidegger), para os quais o indivíduo não é senhor de si, ao contrário, é regido em função do seu contexto histórico-político no mundo. Alguns chegam a esvaziar por completo o significado do testemunho enunciado por um indivíduo, definido como primazia da consciência. Qualquer manifestação pessoal é simplesmente concebida como um mero sintoma e não como um núcleo último de interpretação, como destacou o filósofo italiano Gianni Vattimo em "As aventuras da diferença" (VATTIMO, 1988).

Neste caso, as identidades discursivas e todo o movimento de autoidentificação seriam rechaçados, já que seria inconcebível pensar na identidade de um eu dotado de saberes que comanda toda a sua experiência vivida e a reúne em narrativa. De fato, acreditar na supremacia da consciência, sobretudo, quando reduzida ao cogito, consiste em um suntuoso problema.

Em filosofia, sobretudo pós-heideggeriana, há o reconhecimento dessa dificuldade que reforça o hiato histórico entre conhecimento e vida. A crítica e a anunciada morte do sujeito empírico se apresentam com força no movimento pós-estruturalista que promove uma condenação ao esforço dos discursos científicos de compreensão e de elaboração de narrativas de sujeitos. Trata-se de uma das facetas da crise do testemunho, indicada por Vattimo (1988), que atinge diretamente as ciências humanas e sociais.

A fenomenologia apresenta uma tradição de enfrentamento desta questão, cuja expressão se dá também na construção das ciências, a exemplo da Geografia. Nesta perspectiva, a pesquisa é, em si, uma experiência, que se dá de forma compartilhada constituindo-se como um horizonte de sentido e significação. Não se trata de sujeitos de pesquisa ou de pesquisados: são seres-no-mundo em relação, co-existentes e com-viventes. O pesquisar não nos subtrai desta condição, a qual situa corpos-no-mundo em um movimento hermenêutico contínuo voltado para o sentido de desvelamento dos fenômenos.

Esta perspectiva, marcadamente ontológica, no entanto, ainda se apresenta atrelada até certo ponto com a consciência. O movimento que buscamos toma outro caminho na tradição fenomenológica: o da ética da 
alteridade de Emanuel Lévinas (1905-1995). Nesta, o Outro é incognoscível e é anterior à consciência, à epistemologia, à ontologia e à própria ciência. Nela a pesquisa se realiza em resposta à alteridade, a uma convocação de natureza ética, na qual o Outro desloca e provoca o desembriagamento do eu (deslocando a pesquisadora), exercendo assim um papel de docência.

\section{Alteridade e identidade Payayá}

Tomar este caminho apresenta o insondável desafio de construção de uma investigação em Geografia que tenha na ética não um procedimento metodológico, mas um imperativo da relação com o Outro. Isso significa, entre outras coisas, que o tema e a própria pesquisa são respostas a esta convocatória, expressão da urdidura que se fez na relação com esse Outro que, no caso desta investigação, é o povo indígena Payayá.

Trata-se de um povo que fora muito numeroso e que habitava uma ampla região nos estados da Bahia e de Sergipe, com limites difíceis de precisar, embora a literatura historiográfica, a exemplo de Solon Santos (2011), defenda que, no século XVII, os Payayá habitavam uma extensão no sentido leste e oeste que abrangia desde o Médio São Francisco ao Recôncavo Baiano. Mas, o sentido exterminador e irremissível do imperialismo colonial, manifesto desde o século XVI, os obrigou ao silenciamento e à negação de sua condição indígena, como única via de escapar de um fim alcantil. Com efeito, eles conviveram em absconso, durante muitos anos, com o decreto de seu aniquilamento, fundamentado pela literatura (OTT, 1958; LEMOS, 1995). Recentemente, no início da década de 1990, a partir de um movimento germinado no Povoado da Cabeceira do Rio, no município de Utinga - Bahia, é que eles passaram a lutar pelo direito de afirmação e respeito da sua identidade, conseguindo desde então pelo menos duas grandes conquistas: a certificação, no ano de 2012, de sua identidade indígena emitida pela Fundação Nacional do Índio, a Funai e, no final de 2018, a cessão do Governo do Estado da Bahia da primeira porção de seu território.

No entanto, esse movimento se deparou com o esquecimento e com a negação de suas raízes indígenas. O esquecimento é patente em uma nova geração, oriunda de uma geração que, de tanto tentar olvidar, acabou sendo 
convencida que perderam toda a indianidade. No entanto, sustentado pelo epicentro do movimento, muitos reviraram seu passado e trouxeram à tona experiências tonificantes da sua plurivocidade corporal e da sua geograficidade, fundantes do seu existir. Passaram a endossar o grito de uma catarse: "eu sou Payayá"!

No lapso de tempo no qual as narrativas manifestas não desvelaram algum sentido indígena, não existiam de fato os Payayá? Estavam eles mortos por caminharem como sonâmbulos à luz da racionalidade colonial? Eles deixaram de ser Payayá quando esqueceram ou desconheceram o seu passado, ainda que vivendo cotidianamente uma filosofia indígena traduzida em outros modos de se relacionar com o ambiente? O discurso de um eu que domina toda a sua exposição pela consciência não pode ser fundamento visceral da identidade. Não se pode ignorar toda ascese à qual os Payayá foram submetidos ao longo da vida. Os deslocamentos aleivosos operaram uma certa aturdisse da consciência.

Isso não quer dizer que devamos desprezar a consciência, até porque o limbo no qual os Payayá foram lançados acentuou o caráter irremissível do passado, ajudando a fundamentar o próprio caminho de libertação do fatalismo feiticeiro que ela comporta. Todavia, a consciência não é o fundamento da identidade. Ao contrário, na consciência a singularidade pode ser confundida com a universalidade, à medida que os Payayá são percebidos como unicidade corporal formada pela reunião e pela multiplicidade de eus. A identidade perde assim todo seu caráter de individuação e passa a ser mera síntese operacional da diferença, revestida pelo sentido universal do conceito de indivíduo e também de coletivo.

O que une os Payayá não pode ser entendido de imediato como consciência. Eles sinalizam que a proximidade é dada pela significação ética do lugar, sensibilidade de um aqui, que não é uma qualquer apercepção da consciência em relação a um ponto no espaço euclidiano. Essa proximidade reverbera na identidade, que ganha outro sentido irredutível à lógica tautológica.

A escuta da voz Payayá tem nos levado a repensar a espacialidade da existência e a colonialidade na ciência geográfica. Muitos estudos, na contemporaneidade, continuam a dar relevo a um sentido geográfico da identidade ou a uma espacialidade fundante da experiência humana, desafiando 
com isso várias críticas aludidas a um suposto enraizamento e obduração do devir. No entanto, com raras exceções, eles têm hipostasiado a lugaridade e a territorialidade, especialmente, como resultados pelos quais a consciência produz significados a partir da relação cognitiva com o mundo.

O esforço em romper certa cisão entre sujeitos, pessoas ou povos de suas respectivas espacialidades, a exemplo de uma afirmação recorrente de que lugares são pessoas e vice-versa, acaba reduzido a uma atividade cognitiva na qual a conexão com o espaço se dá mediante uma ação objetal de uso ou de referência para si e por si. Os lugares são assim para um eu. A própria noção de consciência e de intencionalidade perde, nesse âmbito, sua transitividade quando correlata ao cogito cartesiano.

Investigar esse sentido geográfico implica romper as molduras da esfera ontológica, pois não se trata de um círculo hermenêutico fechado no qual o ser se desvela no ente e este se verbaliza no seu ser. Não ignoramos a ontologia, embora ela esteja frequentemente associada ao psiquismo da guerra, sobretudo, no bojo das críticas à totalização do ser, oriundas do pensamento levinasiano e descolonial latino-americano. No entanto, primamos pela ética, fundada em resposta a uma alteridade. O Outro não se dispõe como conteúdo acessível, aberto ao desvelamento. A significância se dá pelo retorno do sem-sentido, ou seja, do incompreensível. O próprio sentido exige seu transbordamento, ou a própria inversão do sentido em sem-sentido, pois do contrário, a radicalização do para-outro (alteridade), necessária para romper a tautologia da identidade, se dissolveria em para si (LANNOY, 1990; FABRI, 2008).

Para tanto, tensionados pela ousadia do movimento do pensamento levinasiano, recorremos à fenomenologia, partindo e tendo como referencialidade a experiência com os Payayá, mas desprendendo-se também dela, para possibilitar um devir em que a substancialidade da percepção seja desestabilizada. Paradoxalmente, esse movimento não consiste no abandono da fenomenologia, mas na sua genuína fidelidade, como tem insistido Sebbah (2009) ao interpretar a proposta de Lévinas em defesa da intermitência da fenomenologia e da reinvindicação da metafísica.

Buscando marcar essa particularidade do sentido ético que conforma a significação do um-para-o-outro, optamos pela designação metafenomenologia, utilizada pelo filósofo da desconstrução Jacques Derrida em uma 
de suas publicações muito difundida sobre o pensamento de Emmanuel Lévinas, "Violência e metafísica" (DERRIDA, 2014). O prefixo "meta" almeja dar ênfase à transgressão da fenomenalidade, à metafísica expressa pela transcendência que gravita em torno da ideia de infinito. Ele diz sobre a necessidade de resguardar a distância apesar de toda proximidade dada pela inquietação de acolhimento do outro, pois somente assim é possível a radicalidade da alteridade: o Outro permanecendo exterioridade absoluta, não como referência teológica, mas de modo a não reduzi-lo ao imperialismo do Mesmo.

Este posicionamento exige mudanças na própria forma de fazer uma investigação geográfica ou, mais profundamente, no endereçamento de uma reflexão no âmbito da ciência geográfica. Em que se pese as diferenças entre um pensamento filosófico e uma reflexão científica, a radicalidade da alteridade colocada por Lévinas traz implicações éticas fundamentais que reverberarão na própria concepção de lugar, de identidade e, em último caso, da própria perspectiva fenomenológica na Geografia.

O Outro, no entanto, não está limitado ao homem, como na filosofia levinasiana. Nisso, a perspectiva dos Payayá (compartilhada por muitos dos chamados "ameríndios") nos provoca um reposicionamento. O rio, a mata, os animais, as montanhas constituem uma alteridade para além do humano, ao mesmo tempo em que, no sistema colonial de formação do território brasileiro, o Outro homem, especialmente o europeu, assumiu-se como centralidade para a demarcação dos indígenas enquanto alteridade. Entretanto, esta alteridade como simples campo da diferença ou daquilo que ordinariamente é visto como um reflexo de um "não eu", a rigor não condiz com a absolutez do Outro nos termos aqui defendidos, pois esta não implica reconhecimento alicerçado em nenhum conhecimento.

A concepção de alteridade dos Payayá nos aproxima do pensamento ambiental latino-americano, especialmente por meio do sociólogo mexicano Enrique Leff, que se apoiou em Lévinas para refutar a transcendência como relação da consciência e o pensamento enquanto real imanente, argumentando uma ética para além do ser, na qual o absolutamente Outro é o ambiente. Em "Epistemologia ambiental" (LEFF, 2007) o ambiente é considerado para além da ontologia, como "outro modo que ser" levinasiano no movimento de desconstrução da racionalidade do mundo. 


\section{Yapira: "aqui" Payayá}

A noção de povo como coletividade uníssona certamente é fantasiosa, pois qualquer coletivo possui suas divergências internas (BUTLER, 2018). Mas 'o 'povo' não deve ser confundido com 'comunidade política', como um todo indiferenciado da população e dos cidadãos de um Estado $[\ldots]^{\prime \prime 3}$ (DUSSEL, 2015, p. 227). No âmbito Payayá, povo é uma relação fundamentada na responsabilidade mútua, cujo elo é o tugûy (sangue), mas principalmente a geograficidade manifesta a partir do sentido ético das relações de alteridade, pelo qual os rios, as plantas, os animais, o Outro Payayá e toda a ambiência do lugar ou da Yby significam a intimação do um pelo outro. Esta proximidade envolve a situação, mas não se reduz a procedimentos ontológicos, pois também diz respeito ao para-lá ou ao sem-sentido pelo qual a Gameleira (árvore brasileira pertencente ao gênero Ficus da família Moraceae - LORENZI, 2009) é também Payayá, implicação da vivência do um-para-outro.

Notadamente, a alteridade não se restringe a um povo, pois isso seria perdê-la, à medida que o Outro estaria limitado a determinadas escalas geográficas, sociais ou biológicas. Falar em alteridade restritiva chega a soar como oximoro. Entretanto, o movimento não é de uma redução da alteridade à noção de povo, mas de destacar que povo, apesar da unidade, envolve ele mesmo uma alteridade, podendo ser ela o próprio elo, manifesto na unicidade da relação. De qualquer forma, isto nos leva a uma generalização, o que pode alimentar representações.

O coletivo, implicado na noção de povo, pode dar voz ao anonimato, quando visto a partir da generalidade abstrata ou da síntese de eus. Sob essa ótica, facilmente os outros conformam uma espessura fantasmagórica, não sendo eles ninguém em particular e, simultaneamente, cada um é visto por sua representação (GROS, 2018). Esta situação insidiosa ratifica a importância da responsabilidade do Eu, que não pode eximir-se absconso na névoa difusa da coletividade.

Os Payayá constituem um coletivo, cuja organização explicita a força da representação, a exemplo do cacique e do pajé. De fato, alguns podem ficar invisibilizados ocultando-se sob a carapaça de suas lideranças ou ficando silentes, quando constrangidos por elas. No entanto, não podemos 
igualar consciência comprometida (proximidade enquanto intencionalidade) com a ética do um-para-outro (proximidade irredutível à tematização), a ambivalência e a preponderância da situacionalidade podem conformar um certo imbróglio neste sentido.

Porém, não é possível mensurar a ética de cada um, exigindo do Outro reciprocidade como se as relações fossem comerciais. É justamente na diferença, na não-coincidência, que a ética se desenha. A dissimetria da relação é fundamental à proximidade enquanto um-para-outro. Um Payayá não está à medida do Outro.

O foco na relação entre Eu e o Outro não elimina o coletivo, ao contrário, a vivência em comunidade é uma maneira de reverberar a fissão de si, fazendo do Eu um outro. Ainda que este movimento não seja oriundo da experiência (sujeito intencional), é possível que na desmesura da própria relação vivida se expresse o pneuma da diástase da identidade (LIMA, 2019).

Que significa o coletivo Payayá ante as inúmeras tentativas de seu aniquilamento? O reconhecimento de uma aldeia Payayá na Yapira (nascente do rio), povoado Cabeceira do Rio, município de Utinga, estado da Bahia, tem motivado que muitos Payayá que atualmente vivem sob a negação de sua alteridade em distintos municípios do interior dos estados de São Paulo, e principalmente da Bahia, contactem as lideranças Payayá para partilhar suas histórias e experiências sufocadas pela incessante violência totalitária. Este é um movimento crescente, inolvidável na cerimônia que marcou a entrada no Território Indígena Payayá, no dia 4 de janeiro de 2019, quando narrativas emocionadas ressaltaram a centralidade da Yapira, tal como Arnaldo que veio do vale do rio Paraguaçu para compartilhar sua trajetória enquanto Payayá ao tempo que designava a irrupção da Yapira como o pulsar do coração do Paraguaçu. Acolhido e interpelado pelo próprio lugar, Arnaldo expressou seu pertencimento a Yapira, mesmo sendo aquela a primeira vez em que pisava lá. Ali era também seu aqui, e de tantos outros que têm manifestado a ligação a Yapira como rosto de Yby.

Não há um essencialismo que limita os Payayá à Yapira. Não se trata de uma referencialidade do tipo geométrica. Como afirmou Sergio Valzania (2012) em nota introdutória à obra de Farinelli, "A invenção da Terra", estamos muito acostumados a condensar paisagens em uma rápida 
impressão, a nos deslocarmos por centenas de quilômetros em poucas horas por traços impressos no mapa rodoviário (situação mais acentuada quando viajamos de avião), por meio dos quais podemos reduzir cidades a bolinhas que as representam. Os Payayá, sobretudo os que atualmente estão acima da faixa etária dos 60 anos, conhecem o extenso sertão da Bahia e os caminhos para São Paulo intercalando trechos a pé, de trem e em "pau-de-arara".

Este modo de viajar possibilita "uma imagem própria do percurso ao longo do qual se move", cujo "[...] andar, de alguma maneira cria", pois ele provoca "uma emoção forte, que não deriva apenas do cansaço, da meditação à que somos obrigados ou da produção de endorfina, a morfina natural que nosso cérebro secreta sob o esforço de nos ajudar a suportar o cansaço" (VALZANIA, 2012, p. 8).

Este trânsito dos Payayá deixou muitas marcas, pois ele mesmo é assinalado pelo peso do passado colonial. Os Payayá conhecem depressões intermontanas e interplanáliticas semiáridas e regiões mamelonares tropical-atlânticas florestadas do território baiano não somente pelo modo de nele circular, mas também pelas reminiscências que tatuaram o seu aqui. Embora coexistindo com vários outros povos na Bahia, a história colonial denuncia que eles eram numerosos e viviam em uma área extensa que abrangia a maior parte do atual estado baiano. Geometricamente, isto significa que o aqui poderia ser em muitos possíveis lás.

Mas é na Yapira onde os Payayá atualmente desejam ser inumados. Os que moram longe desta recente centralidade, mesmo em lugares simbolicamente fundamentais à trajetória Payayá, têm manifestado essa solicitude tumular. Por que ser enterrado na Yapira, se mesmo nela a violência é brutal e não considera nem as exéquias, inclusive a do Sacambuasu, grande cacique Payayá que foi morto e enterrado nessas terras no marcante ano de 1673 (Guerra do Aporá4)?

Porque nela o silêncio ressoado irrompeu em gritos que farpearam a razão cínica do Mesmo. Porque nela o elo coletivo tem conseguido que as ações desenraizadoras e a alergia quizilenta ao Outro não continuem imunes na vala das casualidades comuns. Porque nela foi possível reunir condições concretas para a efetivação da ética, que torna o lugar conhecido, o inapreensível. Porque nela a raiz da Gameleira vive e faz da Yby o aqui e 
o para-lá, (sem)sentido da alteridade. Porque nela o grito do Sacambuasu ecoa e fortalece o chamado ético.

Na Yapira e adjacências, os topônimos Poço Preto, Lagoa da Onça, Maracaiá (gato pintado), Grama, Utinga, dentre outros, são designações Payayá que marcam sua geograficidade e historicidade. Na Yapira conseguiu-se minimamente condições para afirmar a alteridade, acolhimento que possibilita uma outra hospitalidade: metafenomenologia pela qual o lugar é o outro que desubstancializa a identidade.

Para os Payayá, a Yapira é um lugar, mas este não se confunde com uma fortaleza exclusiva, nem com a relação de propriedade associada ao Território Indígena Payayá, institucionalmente reconhecido. Lugar é alteridade pela qual eles se sentem obrigados a acolher. A Yapira não se reduz a uma superlatividade coagulada pela consciência.

No entanto, a Yapira não é qualquer lugar. Sua localização não é uma presença sobre uma extensão abstrata. Entretanto, ela não está somente relacionada aos sentidos. Na Yapira e no sertão da Bahia, mais amplamente, a história confere sentidos que tonificam a razão deste aqui Payayá. A tomada de consciência do passado irremissível, elucidado nos próprios topônimos, contribui para a aderência dos Payayá à ambiência sertaneja. Mas, esta situacionalidade também se dá pela tensão entre sentido e sem-sentido.

Na tensão entre o visível e o invisível, entre a consciência situada e a subjetividade anárquica, destaca-se a geograficidade. Este modo de ser Yby (ser terra) pode ser interpretado como expressão do vivido e do tematizado que possibilita saberes partilhados no âmbito da cultura Payayá. Estes saberes podem potencializar o acolhimento do lugar, não enquanto definição de um modelo para acolher, mas como fomento às condições de efetivação ética. Mas, os Payayá vivem, sobretudo, a partir do sentido ético que os impõe acolher o lugar, que também não é continente que reúne conteúdos (plantas, rios, pessoas etc.). Ele também é um Outro: alteridade que anima a pneumatologia Payayá, remetendo ao movimento de desembriagamento do eu. Trata-se de uma responsabilidade para com o lugar, o atendimento a um chamado que se expressa como acolhimento do rosto que não deixa de ser terra, abertura à sua insubstancialidade.

Terra que se pisa, caminhando sob trilhas de águas, ou trilhas feitas pelos pés. Mas é também as marcas da terra nos corpos, pela resistência, 
pela exigência, pela demanda de todo o dia. É também o ar que, nesta pneumatologia, não se realiza fora da terra: é ela terra também. É pelo ar que a fumaça ritual dos cachimbos que exumam ervas, colhidas da terra, passam pelos corpos Payayá inspirando e expirando, tornando este corpo elo terra-ar a diástase de suas identidades. Compartilhar um cachimbo, circundar alguém com a fumaça ou espalha-la no ar da Yapira são maneiras de misturar-se, sem fusão, à terra. Imersão como inerência topológica pela respiração.

Os cantos ou thorés, realizados em diferentes ocasiões, também expressam este acolhimento. Marcam, sobretudo, a desmesura de um aproximar-se da terra, seja nas ocasiões festivas, nas reuniões espirituais, ou em um serão juntos em uma casa. Com os pés descalços ou calçados, cantando em conjunto, com maracás e corpos em oscilação ritmada, trata-se de um convite para celebração.

Não é de admirar, portanto, que a cerimônia de 4 de janeiro de 2019, no Território Indígena Payayá, tenha sido iniciada pelo Cacique Juvenal Payayá com uma roda de thoré. Aquela cerimônia não foi só política, marcada pela hostilidade e pela demarcação de posições, mas foi também sagrada e de congraçamento. Foi uma recepção, um agradecimento, uma oferenda, um compartilhamento e, sobretudo, uma celebração e um ato de acolher à terra. Ajoelhar-se junto ao solo, despir os calçados e cantar os thorés debaixo da mangueira foram apenas alguns dos momentos deste encontro.

A geograficidade Payayá contrapõe a tarefa colonial de desenraizar pessoas dos lugares, ao tempo que freme à própria noção de enraizamento costumeiramente aludida. Há uma valorização do movimento enquanto ética que transcende a cultura de um qualquer aqui, entretanto, de maneira alguma, a inquietação suscitada se traduz como disjunção da Yby. Estar enraizado, neste sentido, consiste na agudez do ouvir a terra e por ela lutar, apesar de toda a força gravitacional dirigida para extenuar a irrupção da luta. Enraizar-se não é repousar, mas conectar-se à Yby, ao mundo que se faz lugar.

Trata-se de ouvir a Yby e permitir que ela rompa os limites da identidade oriunda do encadeamento do eu a si. O(s) lugar(es) despoja(m) os Payayá, sem alienação, pois o Outro no Mesmo reascende a própria individuação. O coletivo é reforçado pelo elo inalienável de cada um com 
o todo. A proximidade do lugar é a afecção pela qual a identidade não é lógica, mas topológica. A ética arranca o Eu de sua quizila, provocando uma geograficidade no seio da própria identificação, a maneira do "outro em mim", na expressão levinasiana. O sentido ético desta geografia marca a impossibilidade de calar-se ou de fazer-se surdo ante a proximidade enigmática da Yby, metafenomenologia da alteridade.

\section{Um sentido geográfico para a identidade}

Estes deslocamentos entre a metafenomenologia de Lévinas, o pensamento descolonial latino-americano situado e a geograficidade e historicidade Payayá, em uma dinâmica de mútuos atravessamentos, produzem afastamentos e aproximações que têm, como objetivo, a construção de um sentido geográfico da identidade.

A condição dos Payayá está profundamente entrelaçada com nossa condição histórica e geográfica como brasileiros e latino-americanos. Não em um hibridismo multiforme que deforma para reformar, mas no âmbito da responsabilidade e da ética indeclinável que nos convoca. Neste sentido, esta metafenomenologia da alteridade Payayá nos permite um mergulho nos processos de constituição de identidade e diferença que têm na geograficidade uma de suas manifestações e, ao mesmo tempo, sua fundamentalidade. Assim, o lugar, arrolado nos debates contemporâneos como ligado a perspectivas essencialistas de substancialização, pode receber um outro olhar, que lhe atribuiu centralidade no debate da identidade em seu sentido geográfico.

A partir do Cacique Juvenal Payayá, sua família e seus parentes, fomos ao encontro dos Payayá, seja em Utinga, em outros municípios da Chapada Diamantina, seja nos locais mais distantes para onde migraram (na Bahia e até no estado de São Paulo). Assim, pela presença e pelo presente, questionamos a história de extermínio dos Payayá sem utilizar a historicidade ou a geograficidade como enquadramento deles. O presente é uma forma de surpreender a própria historiografia colonial, a qual continua sangrando, viva, pois permanece tentando negar a existência deles ininterruptamente.

30. GeoTextos, vol. 15, n. 2, dezembro 2019. J. Lima. 13-33 
O passado não se reduz à consciência no sentido ético aqui empregado, pois este não é correlato de um tempo sincronizável mediante a memória e a história. Porém, para destacá-lo, recorremos às reminiscências sobre e dos Payayá, constituindo assim uma significação desse passado irremissível enquanto uma sincronia. A transcendência e a diacronia se fazem, paradoxalmente, tematização, uso do verbo ser e sincronização. Entretanto, não entendemos se tratar da repetição de uma ontologia, apesar de não negarmos a condição ontológica. Reconhecemos esse limbo, mas é justamente a situacionalidade, e, portanto, a história, a historicidade e a geograficidade dos Payayá que contribuem para contrapor a universalidade.

A situacionalidade faz parte da ontologia, da esfera do Dito, pois é manifestação do conhecimento, no entanto, essa tensão conformada diz também sobre o ético no ontológico, subvertendo-o, repercutindo uma ambiguidade. Nesta, simultaneamente, o discurso deste texto e da situação dos Payayá estão localizados no tempo sincrônico e reminiscente, bem como no tempo diacrônico irredutível à consciência.

Atualmente, a vida e a identidade Payayá estão ligadas ao "aqui" Yapira, enquanto lugar, que permite a evasão de si (não do lugar), enquanto fissura necessária à identidade Payayá, cujo sentido geográfico significa uma ética da alteridade.

\section{Notas}

1 Artigo composto a partir da tese de doutorado "O sentido geográfico da identidade: metafenomenologia da alteridade Payayá" (LIMA, 2019).

2 Lévinas (2011) criou a expressão “outramente que ser”, também descrita como “outro modo que ser", para se referir à alteridade em seu sentido ético que não se confunde com a ontologia, por isso não diz respeito a outro modo de ser, nem se confunde com o Outro do ser.

3 Tradução nossa do original: “el 'pueblo' no debe confudirse con la mera 'comunidad política', como el todo indiferenciado de la población o de los ciudadanos de un Estado [...]".

4 Guerra promovida pelo governo da colônia, entre 1669 e 1673, objetivando intensificar o esforço de desbaratamento e extermínio dos Payayá. 


\section{Referências}

ARAÚJO, Frederico G. B. "Identidade" e "território" enquanto simulacros discursivos. In: ARAÚJO, Frederio G. B.; HAESBAERT, Rogério (Org.). Identidades e territórios: questões e olhares contemporâneos. Rio de Janeiro: Access, 2007. p.13-32.

BUTLER, Judith. Corpos em aliança e a política das ruas: notas para uma teoria performativa de assembleia. Tradução de Fernanda S. Miguens. 2 ed. Rio de Janeiro: Civilização Brasileira, 2018.

DERRIDA, Jacques. Violência e metafísifca: ensaio sobre o pensamento de Emmanuel Lévinas. In: DERRIDA, Jacques. A escritura e a diferença. Tradução de Maria Beatriz M. N. da Silva, Pedro L. Lopes e Pérola de Carvalho. São Paulo: Perspectiva, 2014. p. 111-223.

DUSSEL, Enrique. Filosofía de la liberación. México: FCE, 2011.

DUSSEL, Enrique. Filosofías del Sur: descolonización y transmodernidad. Buenos Aires: Akal, 2015.

FABRI, Marcelo. "Fim do mundo" e fenomenologia do humano do pré-cultural ao intercultural. In: SOUZA, Ricardo T. de; OLIVEIRA, Nythamar F. de. (Org.). Fenomenologia hoje III: biotética, biotecnologia, biopolítica. Porto Alegre: EDIPUCRS, 2008. p. 401-415.

GROS, Frédéric. Desobedecer. Tradução de Célia Euvaldo. São Paulo: Ubu Editora, 2018.

HEIDEGGER, Martin. Identidade e diferença. In: HEIDEGGER, Martin. Conferências e escritos filosóficos. Tradução de Ernildo Stein. Coleção Os Pensadores. São Paulo: Nova Cultural, 1999. p. 173-200.

HENRY, Michel. A barbárie. Tradução de Luiz Paulo Rouanet. São Paulo: Realizações Editora, 2012.

LANNOY, Jean-Luc. D’une ambiguité. Etudes Phénoménologiques, v. 6, n. 12, p. 11-44, 1990.

LE BOSSÉ, Mathias. As questões de identidade em geografia cultural - algumas concepções contemporâneas. In: CORRÊA, Roberto L.; ROSENDAHL, Zeny (Org.). Paisagens, textos e identidade. Rio de Janeiro: EdUERJ, 2004. p. 157-179.

LEFF, Enrique. Epistemologia ambiental. Tradução de Sandra Valenzuela. São Paulo: Cortez, 2007. 
LEMOS, Doracy A. Jacobina, sua história e sua gente/memórias. Jacobina, 1995.

LÉVINAS, Emmanuel. A filosofia e o despertar. In: LÉVINAS, Emmanuel. Entre nós: ensaios sobre a alteridade. Tradução de Pergentino Pivatto et. al. Petrópolis: Vozes, 2010. p. 103-116.

LÉVINAS, Emmanuel. De outro modo que ser ou para lá da essência. Tradução de José L. Pérez; Lavínia L. Pereira. Lisboa: Centro de Filosofia da Universidade de Lisboa, 2011.

LIMA, Jamille da S. $\mathbf{O}$ sentido geográfico da identidade: metafenomenologia a alteridade Payayá. 2019. Tese (Doutorado em Geografia) - Instituto de Geociências, Universidade Estadual de Campinas, Campinas.

LORENZI, Harri. Árvores brasileiras: manual de identificação e cultivo de plantas arbóreas nativas do Brasil. v. 2, 3 ed. Nova Odessa: Instituto Plantarum, 2009.

OTT, Carlos. Pré-história da Bahia. Salvador: Progresso Editora, 1958.

SANTOS, Boaventura de S. Para uma sociologia das ausências e uma sociologia das emergências. In: SANTOS, Boaventura de S. Conhecimento prudente para uma vida decente: um discurso sobre as ciências revisitado. 2 ed. São Paulo: Cortez, 2006.

SANTOS, Solon N. A. dos. Conquista e resistência dos Payayá no Sertão das Jacobinas: tapuia, tupi, colonos e missionários (1651-1706). 2011. Dissertação (Mestrado em História) - Faculdade de Filosofia e Ciências Humanas, Universidade Federal da Bahia, Salvador.

SEBBAH, François-David. Lévinas. Tradução de Guilherme João de Freitas Teixeira. São Paulo: Estação Liberdade, 2009.

VALZANIA, Sergio. Nota. In: FARINELLI, Franco. A invenção da terra. Tradução de Francisco Degani. São Paulo: Phoebus, 2012. p. 7-8

VATTIMO, Gianni. As aventuras da diferença: o que significa pensar depois de Heidegger e Nietzsche. Lisboa: Edições 70, 1988.

Recebido em: 04/11/2019

Aceito em: 19/11/2019 